\title{
Phytochemical Profiles and Antioxidant Activity of Legumes Consumed in Botswana
}

\author{
Sarah Tshepho Pona Matenge \\ Department of Research, Boitekanelo College, Gaborone, Botswana \\ Email address: \\ stpmatenge@gmail.com \\ To cite this article: \\ Sarah Tshepho Pona Matenge. Phytochemical Profiles and Antioxidant Activity of Legumes Consumed in Botswana. Journal of Food and \\ Nutrition Sciences. Vol. 8, No. 4, 2020, pp. 103-107. doi: 10.11648/j.jfns.20200804.15
}

Received: June 18, 2020; Accepted: July 1, 2020; Published: July 30, 2020

\begin{abstract}
Legume consumption has been consistently linked with lower risk of cardiovascular disease (CVD) and Coronary heart disease (CHD), as a result from their unique phytochemicals. Studies investigating phytochemical profiles and antioxidant activity of legumes in Botswana are limited. Five legume varieties were studied. All the legumes showed a significant amount of total phenolic acids and flavonoids ranging from 64.83 to $828.69 \mathrm{mg}$ of gallic acid equiv/100 $\mathrm{g}$ of sample, DW and from 85.36 to $410.99 \pm 21.24 \mathrm{mg}$ of catechin equiv/100 g of sample, DW respectively. Their antioxidant activity ranged from 50.7 to $114.6 \mathrm{mg}$ vitamin $\mathrm{C} / 100 \mathrm{~g}$ of DW. In this study, there was a positive correlation between TPCs and PSC value of the samples $\left(\mathrm{R}^{2}=0.9940, \mathrm{P}<0.01\right)$. The higher TPCs resulted in higher antioxidant activity, an indication that phenolics were the major contributors to antioxidant activities. Chlorogenic, caffeic, $p$-coumaric, and ferulic acid were detected in all Cowpea varieties (Cowpea-Thamagana Speckle, Cowpea-Inia, and Cowpea-Red). The results from the study emphasize the importance of these legumes as a source of phenolic acids and antioxidants which could contribute to their health promoting properties and prevention of some diseases.
\end{abstract}

Keywords: Legumes, Phytochemicals, Phenolics, Flavonoids, Antioxidant Activity, HPLC

\section{Introduction}

Legumes belong to the family Leguminosae [1] that are used as food and play an important role in the traditional diets in developing countries, especially in Sub-Saharan African countries where they complement the lack of proteins from cereals, roots, and tubers [2].

As the shortage of food continues to be a major problem in Africa, these legumes are being promoted more than before in order to alleviate the protein-energy malnutrition $[3,4]$. In addition to proteins, legumes are also considered a good source of complex carbohydrates, displaying a low glycemic index and high content of fibers, polyunsaturated fatty acids (PUFAs), dietary fiber, contain significant amounts of vitamins and minerals [5, 6], and low in fats [7].

Research has shown that legumes are rich in phytochemicals, that contain many bioactive compounds which are beneficial to health in addition to the identified nutrients such as proteins, vitamins and minerals [8]. The dominant phenolic compounds present in leguminous seeds are the flavonoids, phenolic acids and procyanidins [9].
These compounds inhibit many chronic diseases linked with cancer, inflammation, atherosclerosis, and aging caused by free radicals $[8,9,10]$. Thus, regular legume consumption has been associated with $22 \%$ and $11 \%$ lower risk of coronary heart disease and CVD [11]. Furthermore, consumption of legumes with high phenolic content is correlated to a number of positive health benefits such as hypocholesterolemia, and antiatherogeni [12]. Legumes also possess a hypoglycemic effect, reducing the increase in blood glucose after a meal. Legumes therefore are included in the diet of insulin dependent diabetics. Furthermore, consumption of legumes helps prevent osteoporosis [13] and reduces body lipid accumulation [14].

In Botswana, various varieties of legumes are cultivated and consumed as a source of dietary protein. Their presence therefore could be taken advantage of in addressing both macro and micronutrient deficiencies. However, much data has not been obtained on phytochemical constituents in legumes. So far, there has been no report on the 
phytochemical and antioxidant activity of these legumes consumed in Botswana. Thus, the limited information from literature presents a scope for a comprehensive study that will make a list of legumes available with known and tested functional properties. Furthermore, knowledge of the health beneficiary of phytochemical profiles is important to increase consumers' awareness.

Against this background, the objective of this study were to assess the phytochemical profiles including total phenolic content, phenolic acids, flavonoids, and antioxidant activity in legumes consumed in Botswana.

\section{Materials and Methods}

\subsection{Sample Preparation and Extraction of Phenolic Compounds}

Five legume varieties used in this study were provided by Dr. K. Safi of the Department of Agricultural Research, Sebele, Botswana, at the Seed Multiplication Unit (Table 1). The legumes represent the best known and generally the most widely consumed legumes in Botswana especially in the rural communities. The eight legume samples were ground using a kitchen grinder into small sizes that can pass through sieve No. 72 (British Sieve Standards) and stored at $-40{ }^{\circ} \mathrm{C}$ until analysis.

Free phenolic compounds in legume samples were extracted following a procedure adapted from [15].

Table 1. Descriptions of Legume Varieties Used in this Study.

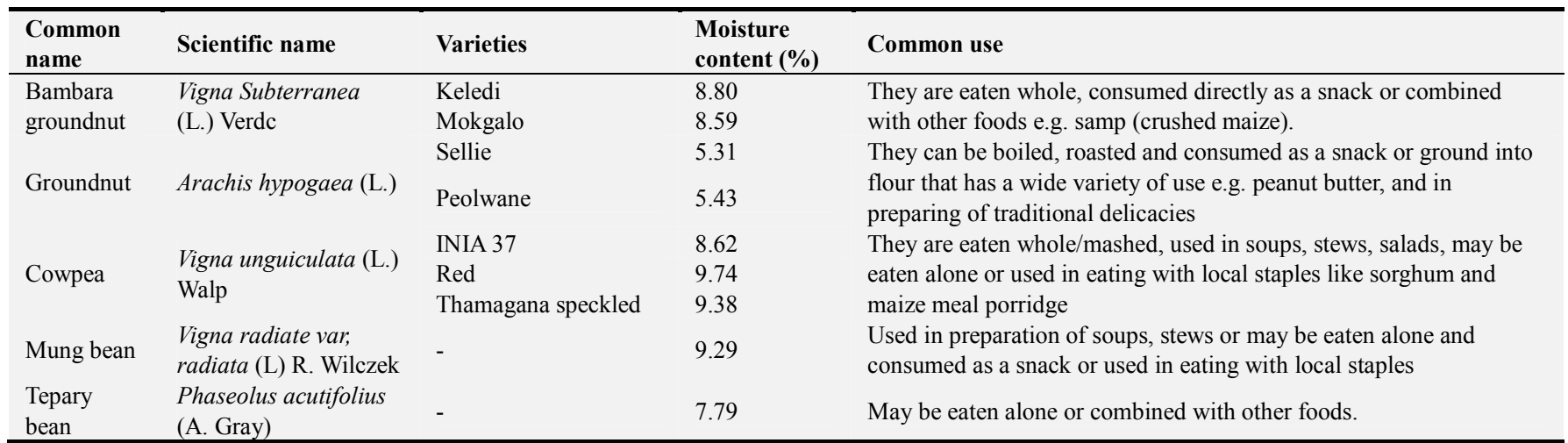

\subsection{Moisture Content of Legumes}

The moisture content was determined by using the ovendry method. A mass of $2 \mathrm{~g}$ of sample was dried in an oven at 105 o $\mathrm{C}$ to a constant weight. The measurements were expressed as percent of dry weight in triplicate (Table 1).

\subsection{Extraction of Phenolic Compounds}

Free phenolic compounds in legume samples were extracted following a procedure adapted from [15]. Briefly, 2 $\mathrm{g}$ of legume flour was blended in Waring blender using 50 $\mathrm{mL}$ of $80 \%$ chilled acetone for $5 \mathrm{~min}$ and samples were homogenized with a Polytron Homogenizer for $3 \mathrm{~min}$. The mixture was then centrifuged at $2500 \mathrm{rpm} g$ for $10 \mathrm{~min}$ and the supernatants were collected in a $25 \mathrm{~mL}$ volumetric flask. All the supernatants were evaporated until $10 \%$ of the supernatants has been retained. The phytochemical extracts were brought to $10 \mathrm{~mL}$ in water and were kept at $-40{ }^{\circ} \mathrm{C}$ until analysis.

\subsection{Determination of Total Phenolic Content}

The total phenolic content of legume varieties was determined using the Folin- Ciocalteu colorimetric method described by [16]. All extracts were diluted 1:20 with Milli-Q water in order to obtain readings that falls within the standard curve concentration range of $0.0-600.0 \mu \mathrm{g}$ gallic acid $/ \mathrm{mL}$. Folin-Ciocalteu reagent was used to oxidized the legume extracts and sodium carbonate was added to the mixture to neutralize the solution. The absorbance was measured at 760 $\mathrm{nm}$. Total phenolic content was expressed as milligrams of gallic acid equivalents (GAE) per $100 \mathrm{~g}$ of dry weight (DW) of sample. Data were expressed as mean $\pm \mathrm{SD}$ of three replications.

\subsection{Quantification of Total Antioxidant Activity by Hydro- PSC Assay}

The total antioxidant activity was determined using the hydrophilic peroxyl radical scavenging capacity (HydroPSC) assay, a method described by [17]. The results were calculated as milligrams of vitamin $\mathrm{C}$ equivalents per $100 \mathrm{~g}$ of DW of sample. Data were reported as the mean $\pm \mathrm{SD}$ of at least triplicates for each sample.

\subsection{Determination of the Total Flavonoid Content}

The total flavonoid content of each legume sample was determined using the sodium borohydride/chloranil-based (SBC) assay as described by developed by [18].

Total flavonoid content was expressed as milligrams of catechin equivalents per $100 \mathrm{~g}$ of DW of sample. Data was reported as mean \pm standard deviation (SD) with at least triplicates.

\subsection{High Performance Liquid Chromatography (HPLC)}

Phenolic acids of Legume extracts were separated in a Waters C18 column ( $5 \mu \mathrm{m}, 250 \mathrm{~mm}$ X $4.6 \mathrm{~mm}$; Grace Vydac, Baltimore, MD) on a Waters HPLC system (Waters Corp., 
Milford, MA). Pure standards used for the identification were, chlorongenic acid, caffeic acid, p-coumaric acid, and ferulic acid. The samples were identified by retention time and absorbance spectrum. Results obtained for the sample extracts were expressed as mean $\pm \mathrm{SD}$ for triplicates.

\subsection{Analysis}

Statistical analysis was conducted using SPSS (Statistics for Social Science) version 18.0 for windows. Differences between means were performed using ANOVA and Turkey's test. All graphical representations were performed using Sigmaplot version 2000 (Aspire Software International, Ashburn, VA). Statistical significance was set at $p<0.05$. All the results were presented as mean \pm SD for at least triplicate for each sample.

\section{Results and Discussions}

\subsection{Total Phenolic Content of Legume Varieties}

All the legumes showed a significant amount of total phenolics (Table 2). Expressed as milligrams of gallic acid equivalent per 100 gram of sample on DW basis (mg GAE/100 g DW), total phenolic contents are presented in

Table 2. A wide variation was observed for phenolic contents and differed significantly with respect to this parameter. The free phenolic content ranged from $646.10 \pm$ 7.62 (Cowpea-Thamaga Speckle) to $35.74 \pm 3.81$ (Tepary Bean) mg of GAE/100 g DW.

Table 2. Total Phenolic Content of Legumes. Values Expressed as Milligrams of GA Equivalents/100 $\mathrm{g} D W$ (mean $\pm S D, n=3$ ).

\begin{tabular}{lll}
\hline Name & Varieties & $\begin{array}{l}\text { Total phenolic }(\mathbf{m g} \\
\text { GAE/100 g DW) }\end{array}$ \\
\hline 1. Cowpea & Thamagana speckle & $646.10 \pm 7.62 \mathrm{a}$ \\
& Red & $488.69 \pm 13.13 \mathrm{~b}$ \\
& Inia 37 & $505.39 \pm 10.56 \mathrm{~b}$ \\
2. Bambara & Mokgalo & $570.02 \pm 8.93 \mathrm{c}$ \\
& Keledi & $61.49 \pm 2.96 \mathrm{~d}$ \\
3. Groundnut & Sellie & $342.25 \pm 7.98 \mathrm{e}$ \\
& Peolwane & $312.79 \pm 6.90 \mathrm{e}$ \\
4. Mung bean & - & $218.72 \pm 5.30 \mathrm{~b}$ \\
5. Tepary Bean & - & $35.74 \pm 3.81 \mathrm{f}$ \\
\hline
\end{tabular}

Values with different letters in each row are significantly different $(\mathrm{p}<0.05)$

Table 3. Antioxidant Activity of Legumes Expressed as PSC values Milligrams of Vitamin C Equivalents/100 $\mathrm{g} \mathrm{DW}$ (mean $\pm S D, n=3)$.

\begin{tabular}{lll}
\hline Name & Varieties & $\begin{array}{l}\text { PSC values (mg vitamin } \\
\text { C equiv/100 g DW) }\end{array}$ \\
\hline 1. Cowpea- & Thamagana Speckle & $74.1 \pm 0.9 \mathrm{a}$ \\
& Red & $67.9 \pm 2.1 \mathrm{a}$ \\
2. Bambara Groundnut & Inia 37 & $61.1 \pm 8.5 \mathrm{a}$ \\
& Mokgalo & $73.3 \pm 4.4 \mathrm{a}$ \\
3. Groundnut & Keledi & $32.1 \pm 2.3 \mathrm{~b}$ \\
& Peolwane & $37.1 \pm 2.2 \mathrm{~b}$ \\
4. Mung bean & Sellie & $32.3 \pm 2.8 \mathrm{~b}$ \\
5. Tepary Bean & - & $39.2 \pm 1.3 \mathrm{~b}$ \\
\hline
\end{tabular}

Values with different letters in each row are significantly different $(\mathrm{p}<0.05)$

The bound phenolic content ranged from $260.60 \pm 63.19$
(Cowpea-Inia 37) to $15.00 \pm 5.77$ (Groundnut-Sellie) $\mathrm{mg}$ of GAE/100 g DW). Cowpea-Thamaga Speckle (646.10 \pm 7.62 $\mathrm{mg}$ of GAE/100 $\mathrm{g} \mathrm{DW}$ ) stood out among all the studied legumes followed by Bambara Groundnut - Mokgalo (570.02 $\pm 8.93 \mathrm{mg} / \mathrm{g}$ ). This can be explained by the fact these legumes possess red integuments which are considered high in phenolic compounds $[18,19]$ as compared to Tepary bean $(35.74 \pm 3.81 \mathrm{mg}$ of GAE/100 g DW) with a white integument which had the lowest free phenolic content. The abundant phenolic content of leguminous seeds indicates that legumes are the principal sources of antioxidant activity in food. The total phenolic content of Tepary Bean extracts is similar to those observed in another study [20].

\subsection{Total Antioxidant Activity in Legume Varieties by PSC}

Antioxidant potentials of legumes have been reported in several studies [21, 22, 23, 24]. However, antioxidant activities were measured by DPPH, TEAC, FRAP, TAC and ABTS assay and therefore difficult to compare our data to that reported in other studies [7, 9, 24, 25].

In this study the total antioxidant activity measured by the PSC assay of the different varieties of legumes was expressed as micrograms of Vitamin C equivalent per 100 grams of DW. The PSC assay is usually employed to estimate antioxidant activity of foods. This assay is simple, reliable, robust, sensitive, and precise and can produce acceptable results comparable to those obtained with similar published assays [26]. The PSC values of total antioxidants of the legume fractions are presented in Table 3. In this study, there was a positive correlation between TPCs and PSC value of the samples $\left(\mathrm{R}^{2}=0.9940, \mathrm{P}<0.01\right)$. The higher TPCs resulted in higher antioxidant activity, and therefore, phenolics were the major contributors to antioxidant activities (Tables $2 \&$ 3 ). Literature shows that the total phenolic content is directly associated with antioxidant activity [7, 20, 24, 27]. Antioxidant activity of phenolics depends on the structure and substitution pattern of hydroxyl groups [28].

\subsection{Flavonoid Content of Legume Varieties}

Flavonoids are widespread plant secondary metabolites, including flavones, flavanols, and condensed tannins. Flavonoids present in leguminous seeds belong to flavanols, flavones, and anthocyanidins [8, 29]. As components of vegetables, fruits, and grains, they have generated interest because of their broad human health promoting effects. Many of these effects are related to their antioxidant properties, which may be due to their ability to scavenge free radicals [8, 29]. There are no reports available to compare total flavonoids of legume varieties studied here. However, a few reports on identification and quantification of flavonoids on common beans [30, 31], cowpea sprouts [31], and, pea [32] were documented. Expressed as milligrams of catechin equivalent per gram of samples on a DW basis, total flavonoids contents of Legume varieties were shown in Table 4. The flavonoid content of Groundnut-Sellie (300.85 \pm $149.03 \mathrm{mg} / \mathrm{g})$ was higher $(\mathrm{p}<0.05)$ than those of the other 
legume varieties followed by Cowpea-Thamagana Speckle $(280.11 \pm 20.21 \mathrm{mg} / \mathrm{g})$. Tepary Bean had the lowest flavonoid

content $(47.19 \pm 33.48 \mathrm{mg} / \mathrm{g})$.

Table 4. Total Flavonoids Content of Legumes Expressed as (Milligrams of Catechin Equivalents/100 g, DW (mean $\pm S D, n=3$ ). Percentage Contribution to Total Flavonoids Content is in Parentheses.

\begin{tabular}{lll}
\hline Name & Varieties & Total flavonoids (mg catechin/100 g DW) \\
\hline 1. Cowpea & Thamagana Speckle & $280.11 \pm 20.21 \mathrm{a}$ \\
& Cowpea-Inia 37 & $235.10 \pm 48.39 \mathrm{a}$ \\
2. Bambara & Red & $229.07 \pm 20.84 \mathrm{a}$ \\
& Mokgalo & $226.28 \pm 39.78 \mathrm{a}$ \\
3. Groundnut & Keledi & $166.89 \pm 67.97 \mathrm{~b}$ \\
& Peolwane & $144.63 \pm 82.68 \mathrm{~b}$ \\
4. Mung bean & Sellie & $300.85 \pm 149.03 \mathrm{ac}$ \\
5. Tepary Bean & - & $172.93 \pm 34.12 \mathrm{~b}$ \\
\hline
\end{tabular}

Values with different letters in each row are significantly different $(\mathrm{p}<0.05)$

Table 5. Composition of the Phenolic Compounds in Legume Extracts Expressed as Micro Grams per Gram of DW (mean $\pm S D, n=3$ ) Revealed by HPL

\begin{tabular}{|c|c|c|c|c|c|}
\hline Sample & Varieties & $\begin{array}{l}\text { Chlorogenic acid } \\
(\mu \mathrm{g} / \mathrm{g} \text { of DW) }\end{array}$ & $\begin{array}{l}\begin{array}{l}\text { Caffeic acid } \\
(\mu \mathrm{g} / \mathrm{g} \text { of } \mathrm{DW})\end{array} \\
\end{array}$ & $\begin{array}{l}p \text {-coumaric acid } \\
(\mu \mathrm{g} / \mathrm{g} \text { of } \mathrm{DW})\end{array}$ & $\begin{array}{l}\text { Ferulic acid } \\
(\mu \mathrm{g} / \mathrm{g} \text { of } \mathrm{DW})\end{array}$ \\
\hline \multirow[t]{3}{*}{ 1. Cowpea } & Inia & $24.95 \pm 0.11$ & $10.29 \pm 0.19$ & $5.19 \pm 0.12$ & $4.25 \pm 0.03$ \\
\hline & Red & $26.90 \pm 0.12$ & $11.02 \pm 0.16$ & $5.26 \pm 0.15$ & $4.13 \pm 0.05$ \\
\hline & Thamagana-Speckle & $17.79 \pm 0.04$ & $10.02 \pm 0.12$ & $5.24 \pm 0.12$ & $4.04 \pm 0.08$ \\
\hline \multirow[t]{2}{*}{ 2. Groundnut } & Sellie & ND & ND & ND & $9.16 \pm 0.07$ \\
\hline & Peolwane & ND & ND & $23.56 \pm 0.67$ & $6.96 \pm 0.52$ \\
\hline \multirow[t]{2}{*}{ 3. Bambara } & Mokgalo & $18.58 \pm 0.04$ & $39.67 \pm 0.01$ & ND & ND \\
\hline & Keledi & $20.84 \pm 0.25$ & ND & $1.25 \pm 0.06$ & ND \\
\hline 4. Tepary bean & - & $110.95 \pm 3.18$ & ND & $2.21 \pm 0.11$ & $5.95 \pm 0.11$ \\
\hline 5. Mung bean & - & ND & ND & $18.12 \pm 0.37$ & $4.26 \pm 0.06$ \\
\hline
\end{tabular}

\subsection{HPLC Analysis}

The phenolic acids of Legume varieties were further evaluated by HPLC. Expressed as $\mu \mathrm{g} / \mathrm{g}$ DW sample, quantities of chlorogenic, caffeic, p-coumaric, and ferulic acids were either less or not detected in legume extracts. The levels of phenolic acids varied from $17.79 \pm 0.04-110.95 \pm$ $3.18 \mu \mathrm{g} / \mathrm{g}$ DW sample for chlorogenic acid, $10.02 \pm 0.12-$ $39.67 \pm 0.01 \mu \mathrm{g} / \mathrm{g}$ DW sample for caffeic acid, $1.25 \pm 0.06-$ $23.56 \pm 0.67 \mu \mathrm{g} / \mathrm{g}$ DW sample for $\mathrm{p}$-coumaric acid, and 4.04 $\pm 0.08-9.16 \pm 0.07 \mu \mathrm{g} / \mathrm{g}$ for ferulic acid. Chlorogenic, caffeic, p-coumaric, and ferulic acid were detected in all Cowpea varieties (Cowpea-Thamagana Speckle, CowpeaInia, and Cowpea-Red). Tepary bean, exhibited the highest concentration of chlorogenic acid (110.95 $\pm 3.18 \mu \mathrm{g} / \mathrm{g} \mathrm{DW}$ sample) while the lowest concentration was observed in pcoumaric acid $(2.21 \pm 0.11 \mu \mathrm{g} / \mathrm{g}$ DW sample). Among the four components quantified, only little amounts of ferulic acid $(9.16 \pm 0.07 \mu \mathrm{g} / \mathrm{g}$ of DW sample) were detected in Groundnut-Sellie. Bambara-Mokgalo differed from other legumes in its high concentration of caffeic acid (39.67 \pm $0.01 \mu \mathrm{g} / \mathrm{g}$ DW sample) and its lack of other phenolic acids.

\section{Conclusion}

All legumes extracts showed a significant amount of phenolics and flavonoids and antioxidant activity. In this study, Cowpea-Thamagana Speckle, Cowpea-Inia 37, Cowpea-Red and Bambara Groundnut-Mokgalo had the highest antioxidant capacity and could be explained by their higher phenolic contents. Significant positive correlation was observed between phenolics and total antioxidant activity of the different legume extracts. Given the phytochemicals profiles and antioxidant activity contribution of legumes, nutritionists should make a concerted effort to encourage the public to consume more legumes in general.

\section{References}

[1] Bouchenak, M., Lamri-Senhadji, "Nutritional quality of legumes and their role in cardiometabolic risk prevention: a review”, Journal of Medicinal Foods, 16 (3): 185-198. 2013.

[2] Odhav, B., Beekrum. S., Akula. U., Baijnath, H, "Preliminary assessment of nutritional value of traditional leafy vegetables in KwaZulu-Natal, South Africa", Journal of Food Composition and Analysis, 20, 430- 435. 2007.

[3] Butt, M. S., \& Batool, R, "Nutritional and functional Properties of Some Promising Legumes Protein Isolates", Pakistan Journal of Nutrition, 9 (4): 373-379. 2010.

[4] Marathe, S., Rajalakshmi, S. N., Sahayog, N. J., Sharma, A, "Comparative study on antioxidant activity of different varieties of commonly consumed legumes in India" Food and Chemical Toxicology, 49: 2005-2012. 2011.

[5] Amarteifio, J. O., Moholo, D, "The chemical composition of four legumes consumed in Botswana". Journal of Food Composition and Analysis, 11: 329-332. 1998.

[6] Graham, O. H., Vance, C. P, "Legumes: Importance and constraints to greater use:". Plant Physiology, 131 (3): 872877. 2003. 
[7] Campos-Vega, R., Guadalupe, L., Oomah, B, "Minor Components of Pulses and Their Potential Impact on Human Health". Food Research International, 43 (2): 461-482. 2010.

[8] Liu, R. H, "Potential synergy of phytochemicals in cancer prevention: Mechanism of action", Journal of Nutrition, 134 (12), 3479S-3485S. 2004

[9] Amarowicz, R., Pegg, R. B, "Legumes as source of natural antioxidants", European Journal of Lipid Science and Technology, 110: 865-878. 2008.

[10] Liu, R. H, "Health benefits of fruits and vegetables are from addictive and synergistic combinations of phytochemicals", American Journal of Clinical Nutrition, 78 (3), 517S-520S. 2003.

[11] Flight, I., Clifton, P, "Cereal grains and legumes in the prevention of coronary heart disease and stroke: a review" European Journal of Clinical Nutrition, 60 (10): 1145-59. 2006.

[12] Cardador-Martinez, A., Loarca-pina, G., Oomah, B. D, "Antioxidant activity in common beans (Phaseolus vulgaris L.)”, J Agricultural Food Chemistry, 50: 6975-6980. 2006.

[13] Messina, M. J, "Legumes and soybeans: Overview of their nutritional profiles and health effects" American Journal Clinical Nutritional, 70 (3): 439S-450S. 1999.

[14] Pusztai, A., Grant, G., Buchan, W. C. Bardocz, A. F. F. U., Ewen, B, "Lipid accumulation in obese Zucker rats is reduced by inclusion of raw kidney bean (Phaseolus vulgaris) in the diet", British Journal of Nutrition, 79: 213-221. 1998.

[15] Singleton VL; Orthofer R, Lamuela-Raventos RM, "Analysis of total phenols and other oxidation substrates and antioxidants by means of Folin-Ciocalteu reagent method". Enzyme, 299: 152-178. 1999.

[16] Adom, K. K., Liu, R. H, "Rapid peroxyl radical scavenging capacity (PSC) assay for assessing both hydrophilic and lipophilic antioxidants" Journal of Agriculture and Food Chemistry, 53 (17): 6572-80. 2005.

[17] He, X. Liu, D., Liu, R. H, "Sodium borohydride/chloranilbased assay for quantifying total flavonoids", Journal of Agriculture and Food Chemistry, 56, 9337-9344. 2008.

[18] Mesquita, F. R.; Correa, A. D.; Abreu, C. M. P.; Lima, R. A. Z.; Abreu, A. F. B, "Linhagens de feijão (Phaseolus vulgaris L.) composição química e digestibilidade protéica". Ciencia e Agrotecnologia, 31 (4): 1114-1121. 2007.

[19] Cavalcante, R. B. M., Araújo, M. A. D. M., Rocha, M. M., Silva, K. J. D. Moreira-Araújo, R. S. R, "Effect of thermal processing on total polyphenol content in the grain of cowpea cultivars". Revista Ciência Agronômica, 48 (5), 806-810.

[20] Felice, D. L., Sun, J., \& Liu, R. H. (2009). A modified methylene blue assay for accurate cell counting. Journal of Functional Foods, 1, 109-118.
[21] Luo, Y. W., \& Xie, W. H. (2012). Effects of vegetables on iron and zinc availability in cereals and legumes. International Food Research Journal, 19, 455-459.

[22] Yao, Y., Cheng X., Wang, L., Wang, S., \& Ren, G. (2011). Biological Potential of Sixteen Legumes in China. International Journal of Molecular Sciences, 12, 7048-7058.

[23] Ren, S., Liu, Z., \& Wang. P. (2012). Proximate composition and flavonoids content and in vitro antioxidant activity of 10 varieties of legume seeds grown in China. Journal of Medical Plants, 6 (2), 301-308.

[24] Gujral, S., Sharma, P., Gupta, N. \& Wani, A. A. (2013). Antioxidant properties of Legumes and their morphological fractions as affected by cooking. Food Science and Biotechnology, 22 (1), 187-194.

[25] Adom, K. K.; Sorrel, M. E.; Liu, R. H. (2005). Phytochemicals and antioxidant activity of milled fractions of different wheat varieties. Journal of Agricultural and Food Chemistry, 53 (6), 2297-306.

[26] Awika, J. M., Rooney, L. W., Wu, X., Prior, R. L., \& Zevallos, L. C. (2003). Screening methods to measure antioxidant activity of sorghum (Sorghum bicolor) and sorghum products. Journal of Agricultural and Food Chemistry, 51, 6657-6662.

[27] Wojdyło, A., Oszmian, J., Czemerys, R., Antioxidant activity of phenolic acids in 32 selected herbs. Food Chemistry, 105, 940-949. Jan 2001

[28] Mathew, J, Abraham TE, \& Zakaria, ZA. (2015). Reactivity of phenolic compounds towards free radicals under in vitro conditions. Journal of Food Science and Technology, 52 (9), 5790-5798

[29] Li, H., Cao, D., Yi, J., Cao, J., \& Jiang, W. (2012). Identification of the flavonoids in mung bean (Phaseolus radiatus L.) soup and their antioxidant activities. Food Chemistry, 135 (4), 2942- 2946.

[30] Guajardo-Flores, D., García-Patiño, M., Serna-Guerrero, D., Gutiérrez-Uribe, J. A., \& Serna-Saldívar, S. O. (2012). Characterization and quantification of saponins and flavonoids in sprouts, seed coats and cotyledons of germinated black beans. Food Chemistry, 134, 1312-1319.

[31] Owino, J., Mukashyaka, P., Ndayisaba, H., Habimana, V., Ongol, M. P., Thavarajah, D., \& Pushparajah, T. (2014). Phenolic Compound Profiles of Two Common Beans Consumed by Rwandans. American Journal of Plant Science, 5, 2943-2947.

[32] Luthria, A., Singh, K., \& D’souza, M. (2014). In Vitro antioxidant activity of black gram, cowpea, desi chickpea and yellow mustard as affected by sprouting. Journal of Global Biosciences, 3 (1), 385-389. 